\title{
Dietary DL-methionyl-DL-methionine supplementation increased growth performance, antioxidant ability, the content of essential amino acids and improved the diversity of intestinal microbiota in Nile tilapia (Oreochromis niloticus)
}

\author{
Tian-Yu Guo ${ }^{1} \dagger$, Wei- Zhao ${ }^{1} \dagger$, Ju-Yun He ${ }^{2}$, Shi-Yu Liao ${ }^{1}$, Jia-Jun Xie ${ }^{1}$, Shi-Wei Xie ${ }^{1}$, Karthik Masagounder ${ }^{3}$, \\ Yong-Jian Liu ${ }^{1}$, Li-Xia $\operatorname{Tian}^{1}$ and Jin Niu ${ }^{1 *}$ \\ ${ }^{1}$ State Key Laboratory of Biocontrol, Institute of Aquatic Economic Animal and Guangdong Province Key Laboratory for Aquatic \\ Economic Animals, School of Life Science, Sun Yat-sen University, Guangzhou 510275, People's Republic of China \\ ${ }^{2}$ Animal Nutrition, Evonik Degussa (China) Co. Ltd, Guangzhou Branch, Guangzhou, People's Republic of China \\ ${ }^{3}$ Animal Nutrition, Evonik Nutrition and Care GmbH, Rodenbacher Chaussee 4, 63457 Hanau-Wolfgang, Germany \\ (Submitted 20 April 2019 - Final revision received 1 August 2019 - Accepted 23 August 2019)
}

Abstract

The dipeptide DL-methionyl-DL-methionine (Met-Met) has extremely low water solubility and better absorption than other methionine sources (such as DL-methionine and L-methionine) available in the market. Therefore, six diets (D1, D2, D3, D4, D5 and D6) containing 0, 0·07, 0·15, 0·21, 0.28 and $0.38 \%$ Met-Met were formulated to investigate the effects of Met-Met in juvenile Nile tilapia, Oreochromis niloticus (17 g initial body weight). The results indicated that percentage weight gain and specific growth rate of fish fed with D2 and D3 diets were higher than those fed with D1, D4-D6 diets. The levels of total essential amino acid in whole body of fish fed with D3 and D4 diets were significantly higher than those fed the D1 diet. Superoxide dismutase activity and malondialdehyde content have no significant difference in fish fed the diet with or without Met-Met supplementation. Majority of reads derived from the fish intestine belonged to members of Fusobacteria, followed by Bacteroidetes and Proteobacteria. Diversity of intestinal microbiota and total antioxidant capacity in fish fed with D3 diet was significantly higher than that of other groups. Based on the growth results, the authors conclude that the optimal level of Met is $0 \cdot 61 \%$ Met with the addition of $0 \cdot 15 \%$ Met-Met for grower-phase $O$. niloticus.

Key words: Oreochromis niloticus: DL-Methionyl-DL-methionine: Antioxidant capacity: Intestinal microbiota: Growth performance

Tilapia is a commercially important species widely distributed in over 100 countries. It has become the second most commonly cultured freshwater fish after carp in the world $^{(1)}$. Nile tilapia (Oreochromis niloticus) has dominated tilapia aquaculture due to its high nutritional value, high growth rate and yield. Because of its increasing market demands, O. niloticus have also become the most extensively cultured freshwater fish in China since it is introduced in 1978.

The combination of high nutritional value and increasing market demands has stimulated the development of the industry of tilapia-formulated feed. Dietary proteins are primary factors influencing fish growth and feed costs. Fishmeal has been one of the main animal protein sources in the formulated aquafeeds. However, the market price of fishmeal has sharply increased by nearly $300 \%$ in the past decade because of the increasing demand and the restrictions on fishing wild fish ${ }^{(2)}$. Undoubtedly, the growth of aquaculture production is fundamentally unsustainable if fishmeal is still used as the main source of protein for aquafeeds. Consequently, plant protein sources derived from crops such as soyabeans, peanuts, maize or wheat have become frequently used alternative sources of fishmeal in aquafeeds ${ }^{(3)}$. Large-scale application of plant protein in

Abbreviations: CAT, catalase; DL-Met, DL-methionine; EAA, essential amino acids; L-Met, L-methionine; MDA, malondialdehyde; Met, methionine; MHA, methionine hydroxy analogue; OTU, operational taxonomic units; PWG, percentage weight gain; SGR, specific growth rate; SOD, superoxide dismutase; T-AOC, total antioxidant capacity.

* Corresponding author: Jin Niu, emails niuj3@mail.sysu.edu.cn; edls@mail.sysu.edu.cn

$\dagger$ These authors contributed equally to this work and share the first authorship. 
aquafeeds can reduce feed costs, but the application effect of plant protein is unsatisfactory due to nutritional constraints such as imbalance of amino acid composition, presence of antinutritional compounds, poor palatability and poor digestibility ${ }^{(4)}$.

Essential amino acids (EAA) deficiency in formulated fish feed may cause poor growth, immunosuppression and poor diet efficiency ${ }^{(5)}$. Methionine (Met) is considered to be the first limiting EAA in most plant protein sources ${ }^{(6)}$. Supplementation of Met in diets containing higher levels of plant protein is becoming popular. Supplementation with Met in plant protein-based diets can improve growth performance, immune capacity, feed conversion efficiency and body composition, which have been reported in Scophthalmus maximus ${ }^{(7)}$, Pelodiscus sinensis ${ }^{(8)}$, Sparus aurata ${ }^{(9)}$, Oncorbynchus mykiss ${ }^{(6)}$, Litopenaeus vannamei $^{(10)}$, Myxocyprinus asiaticus ${ }^{(11)}$ and Pseudosciaena croce $^{(12)}$. However, the effects of Met, especially Met-Met products, on $O$. niloticus have not been reported. Currently, Met products used in aquafeeds mainly include DL-methionine (DL-Met), L-methionine (L-Met) or methionine hydroxy analogue (MHA) Ca salt, which have also been proven to be utilised by aquatic animals ${ }^{(7,13,14)}$. The bioavailability of different forms of Met is also considered by nutritionists. Studies in fish have shown that the bioavailability of MHA is significantly lower than that of DL-Met ${ }^{(15,16)}$. The difference in the bioavailability of different Met products in aquatic animals may be related to differences in the product leaching in water, absorption rate in the intestine, and bioconversion into L-Met. Undoubtedly, it is necessary to study the bioavailability of different Met products to different aquatic animals.

The dissolution or leaching rate of Met additives in water is one of the important indexes for comparing different Met products. Meanwhile, the efficiency of Met additives to be absorbed and utilised by animals is also very important. The dipeptide DL-methionyl-DL-methionine (Met-Met), developed by Evonik's aqua R\&D group, has excellent physical and chemical properties, such as extremely low water solubility and better absorption than other Met products (such as DL-Met and L-Met) ${ }^{(5)}$. Met-Met additives can improve growth, feed conversion efficiency and intestinal immune function, which have been reported in L. vannamei ${ }^{(5,17)}$ and Ctenopharyngodon idella ${ }^{(18)}$. Because of low water solubility and a lower leaching rate, Met-Met does not represent a risk to the environment ${ }^{(19)}$. Met-Met has the potential to replace supplemental-free amino acid Met in aquafeeds and is an effective source of the EAA L-Met.

Until now, the effect of Met-Met products on O. niloticus has not been reported. The effect of Met-Met on intestinal microflora of fish has not been reported yet. Diversity of intestinal microflora plays a critical role in modulating the fish physiology ${ }^{(20)}$. Intestinal microflora can influence fish feeding, digestion, growth and energy homeostasis ${ }^{(21)}$. Therefore, the main purpose of the present study was to evaluate the effects of Met-Met supplementation on growth performance, antioxidant capacity, body composition and intestinal microbiota of grower-phase O. niloticus. In the present study, optimal Met-Met supplementation for O. niloticus was first reported. Our data contribute to improve the current understanding of the response relationship between Met and fish intestinal microflora. These results might provide a reference for formulated feed of $O$. niloticus.

\section{Materials and methods}

\section{Diet preparation}

Met-Met was obtained from Evonik Degussa (China) Co., Ltd. Guangzhou Branch.

Six isonitrogenous and isolipidic diets (D1, D2, D3, D4, D5 and D6) containing $0 \%$ (control group), $0 \cdot 1,0 \cdot 2,0 \cdot 3,0 \cdot 4$ and $0.5 \%$ Met-Met were formulated, and their proximate composition is shown in Table 1 . The actual concentrations of Met and Met-Met in the six experimental diets are shown in Table 2. The main protein and energy sources used are soyabean meal, rapeseed meal, wheat flour, rice, soyabean oil and soyabean lecithin. Six experimental diets were supplemented with amino acids, such as glycine, lysine, threonine, tryptophan, isoleucine, leucine, valine and histidine, to ensure that the diets were nutritionally adequate for the fish.

Diets were prepared according to the method of Niu et al. ${ }^{(22)}$. Briefly, all dry ingredients were finely ground, accurately weighed and thoroughly mixed and homogenised. Then, the oil mix and distilled water were added to the mixture. The 2.5-mm-diameter puffed pellets were produced by using a puffing apparatus (Institute of Chemical Engineering, South China University of Technology). The pellets were then dried in a forced air oven at $40^{\circ} \mathrm{C}$ until the moisture was reduced to $<10 \%$ and stored at $-20^{\circ} \mathrm{C}$ until used.

\section{Fish and experimental setup}

Juvenile O. niloticus was obtained from Guangdong Provincial Fishery Germplasm Conservation Center (Guangzhou, China). Fish were acclimated to the experimental conditions and fed the control group diet for 2 weeks prior to starting the experiments. A total of 540 fish with an initial body weight of about 17.15 g were randomly assigned into eighteen fibreglass tanks (800 litres, three tanks per diet, thirty fish per tank). Each tank was equipped with a water exchange system and uninterrupted oxygenation system. The conditions of water temperature $\left(26(\mathrm{sD} 1)^{\circ} \mathrm{C}\right)$, dissolved oxygen $(>6 \cdot 0 \mathrm{mg} / \mathrm{l})$, ammonia-nitrogen $(<0.3 \mathrm{mg} / \mathrm{l})$ and nitrite-nitrogen $(<0.10 \mathrm{mg} / \mathrm{l})$ were ensured during the experimental period.

During the experimental period, the fish were fed two times per $\mathrm{d}$ at 08.00 and 17.00 hours, for fifty-six consecutive days, at $5 \%$ of their body weight. At $1 \mathrm{~h}$ after feeding, uneaten feed and faeces were siphoned from tanks. Uneaten feed particles were dried and weighed and used to calculate feed intake. Every morning before feeding, fish were counted in each tank and were recorded to calculate the survival rate.

\section{Sample collection and growth performance analysis}

At the end of the feeding trial, all fish were fasted for $24 \mathrm{~h}$ to enter a basic metabolic state and eliminate the dietary effect. Seventeen fish per tank were randomly collected and anaesthetised with MS-222 (Sigma) and individually weighed. Body weight and feed data were used to calculate the percentage weight gain (PWG), specific growth rate (SGR), feed conversion ratio and protein efficiency ratio. Four fish for the analysis of whole-body composition, four fish for the analysis of muscle composition, and another four fish for the analysis of 
Table 1. Composition and nutrient levels of the experimental diets (\%)

\begin{tabular}{|c|c|c|c|c|c|c|}
\hline Items & D1 & D2 & D3 & D4 & D5 & D6 \\
\hline \multicolumn{7}{|l|}{ Ingredients } \\
\hline Soyabean meal & 29 & 29 & 29 & 29 & 29 & 29 \\
\hline Rapeseed meal & 28 & 28 & 28 & 28 & 28 & 28 \\
\hline Wheat flour & $22 \cdot 02$ & 22.02 & 22.02 & 22.02 & $22 \cdot 02$ & 22.02 \\
\hline Rice & 12 & 12 & 12 & 12 & 12 & 12 \\
\hline Soyabean oil & $2 \cdot 2$ & $2 \cdot 2$ & $2 \cdot 2$ & $2 \cdot 2$ & $2 \cdot 2$ & $2 \cdot 2$ \\
\hline Soyabean lecithin & 1.2 & 1.2 & 1.2 & 1.2 & 1.2 & 1.2 \\
\hline $\mathrm{Ca}\left(\mathrm{H}_{2} \mathrm{PO}_{4}\right)_{2}$ & 2 & 2 & 2 & 2 & 2 & 2 \\
\hline Vitamin premix ${ }^{*}$ & 0.5 & 0.5 & 0.5 & 0.5 & 0.5 & 0.5 \\
\hline Mineral premix $\dagger$ & 0.5 & 0.5 & 0.5 & 0.5 & 0.5 & 0.5 \\
\hline $\begin{array}{l}\text { Ascorbic } \\
\text { phosphate ester }\end{array}$ & 0.1 & 0.1 & 0.1 & 0.1 & 0.1 & 0.1 \\
\hline Choline chloride & 0.2 & 0.2 & 0.2 & 0.2 & 0.2 & 0.2 \\
\hline AQUAVI ${ }^{\circledR}$ Met-Met & 0 & 0.1 & $0 . \overline{2}$ & 0.3 & 0.4 & 0.5 \\
\hline Gly & 0.5 & 0.4 & 0.3 & 0.2 & 0.1 & 0 \\
\hline Lys & 0.6 & 0.6 & 0.6 & 0.6 & 0.6 & 0.6 \\
\hline Thr & 0.2 & 0.2 & 0.2 & 0.2 & 0.2 & 0.2 \\
\hline Trp & 0.1 & 0.1 & $0 \cdot 1$ & 0.1 & 0.1 & 0.1 \\
\hline $\mathrm{Ile}$ & 0.2 & 0.2 & 0.2 & 0.2 & 0.2 & 0.2 \\
\hline Leu & 0.08 & 0.08 & 0.08 & 0.08 & 0.08 & 0.08 \\
\hline Val & 0.2 & 0.2 & 0.2 & 0.2 & 0.2 & 0.2 \\
\hline $\mathrm{His}$ & 0.4 & 0.4 & 0.4 & 0.4 & 0.4 & 0.4 \\
\hline Total & 100 & 100 & 100 & 100 & 100 & 100 \\
\hline \multicolumn{7}{|l|}{ Nutrient levels $\ddagger$} \\
\hline Moisture & 9.35 & 9.73 & 9.54 & 9.49 & 9.46 & 9.63 \\
\hline Crude protein & 30.50 & 30.54 & $30 \cdot 76$ & 30.42 & 30.38 & 30.52 \\
\hline Crude lipid & 5.52 & 4.97 & 4.74 & 4.53 & 5.21 & 4.69 \\
\hline Ash & 7.79 & $7 \cdot 81$ & $7 \cdot 67$ & 7.79 & $7 \cdot 60$ & 7.69 \\
\hline
\end{tabular}

* Vitamin premix provides the following per kg of diet: cholecalciferol $0.6 \mathrm{MIU}$, thiamin $3.6 \mathrm{~g}$, riboflavin $7.2 \mathrm{~g}$, pyridoxine $\mathrm{HCl} 6.6 \mathrm{~g}$, cyanocobalamin $0.02 \mathrm{~g}$, tocopherol $16.5 \mathrm{~g}$, menadione $2.4 \mathrm{~g}$, nicotinic acid $14.4 \mathrm{~g}$, calcium pantothenate $4 \mathrm{~g}$, biotin $0.02 \mathrm{~g}$, folic acid $1.2 \mathrm{~g}$, inositol $30 \mathrm{~g}$, ascorbic acid $100 \mathrm{~g}$; cellulose was used as a carrier.

† Mineral premix provides the following per kg of diet: $\mathrm{P} 120 \mathrm{~g}, \mathrm{Ca} 120 \mathrm{~g}, \mathrm{Mg} 15 \mathrm{~g}, \mathrm{Fe}$ $1.5 \mathrm{~g}, \mathrm{Zn} 4.2 \mathrm{~g}, \mathrm{Cu} 2.1 \mathrm{~g}, \mathrm{~K} 75 \mathrm{~g}$, Co $0.11 \mathrm{~g}$, Mn $1.6 \mathrm{~g}$, Se $0.01 \mathrm{~g}$, Mo $0.005 \mathrm{~g}$, Al $0.025 \mathrm{~g}$, iodine $0.4 \mathrm{~g}$; cellulose was used as a carrier.

$\ddagger$ Measured values.

Table 2. Amino acid composition of six experimental diets (\% DM basis)

\begin{tabular}{lllllll}
\hline Amino acids & D1 & D2 & D3 & D4 & D5 & D6 \\
\hline Met-Met & 0 & 0.07 & 0.15 & 0.21 & 0.28 & 0.38 \\
Met & 0.43 & 0.51 & 0.61 & 0.67 & 0.77 & 0.88 \\
Cys & 0.49 & 0.47 & 0.48 & 0.50 & 0.48 & 0.48 \\
Met-Cys & 0.92 & 0.99 & 1.08 & 1.17 & 1.25 & 1.37 \\
Lys & 1.94 & 1.96 & 1.97 & 1.96 & 1.95 & 1.97 \\
Thr & 1.30 & 1.26 & 1.27 & 1.28 & 1.28 & 1.29 \\
Trp & 0.48 & 0.46 & 0.46 & 0.45 & 0.45 & 0.46 \\
Arg & 1.78 & 1.83 & 1.84 & 1.83 & 1.83 & 1.85 \\
Ile & 1.35 & 1.37 & 1.37 & 1.37 & 1.35 & 1.40 \\
Leu & 2.06 & 2.05 & 2.07 & 2.06 & 2.05 & 2.07 \\
Val & 1.57 & 1.57 & 1.58 & 1.57 & 1.55 & 1.58 \\
His & 1.06 & 1.05 & 1.06 & 1.06 & 1.05 & 1.07 \\
Phe & 1.23 & 1.24 & 1.25 & 1.24 & 1.23 & 1.26 \\
Gly & 1.69 & 1.60 & 1.52 & 1.43 & 1.34 & 1.27 \\
Ser & 1.36 & 1.29 & 1.31 & 1.31 & 1.31 & 1.31 \\
Pro & 1.62 & 1.63 & 1.68 & 1.64 & 1.62 & 1.67 \\
Ala & 1.26 & 1.24 & 1.25 & 1.25 & 1.24 & 1.25 \\
Asp & 2.63 & 2.56 & 2.57 & 2.58 & 2.56 & 2.61 \\
Glu & 5.31 & 5.14 & 5.25 & 5.18 & 5.22 & 5.28 \\
\hline
\end{tabular}

whole-body amino acid composition were used. The whole body and muscle of fish were sampled and stored at $-20^{\circ} \mathrm{C}$ for body composition analysis. Then, five fish were collected and aseptically killed in ice bath, and their liver and gut were rapidly frozen in liquid $\mathrm{N}_{2}$ and stored at $-80^{\circ} \mathrm{C}$ for antioxidant enzymes activity and microbial flora analysis, respectively. All the experiments were conducted in accordance with the recommendations in the Guide for the Care and Use of Laboratory Animals of the National Institutes of Health. The study protocol and all experimental procedures were approved by Experimental Animal Ethics Committee of Sun Yat-sen University.

PWG, SGR, protein efficiency ratio, feed conversion ratio and survival were calculated according to the following equations:

$$
\begin{gathered}
\operatorname{PWG}(\%)=100 \times\left(W_{f}-W_{i}\right) / W_{i} \\
\operatorname{SGR}(\% / \mathrm{d})=100 \times\left(\ln W_{f}-\ln W_{i}\right) / t \\
\text { Survival }(\%)=100 \times N_{t} / N_{0} \\
\text { FCR }=\text { dry feed intake } /\left(W_{t}-W_{0}\right) \\
\text { PER }=100 \times\left(W_{t}-W_{0}\right) /\left(I \times C_{N f}\right)
\end{gathered}
$$

where $W_{f}$ and $W_{i}$ are mean final and initial fish body weights, respectively; $t$ is the duration of the experiment ( $56 \mathrm{~d}) ; N_{t}$ is the number of fish at the end of the experiment and $N_{0}$ at the start; $W_{t}(\mathrm{~g})$ is the total final body weight and $W_{0}(\mathrm{~g})$ total initial body weight; $C_{N f}(\%)$ is the protein content in the feed and $I(\mathrm{~g})$ is the total amount of the feed fed on a dry weight basis.

\section{Chemical analysis of feed and body composition}

The experimental diets and fish samples were analysed in triplicate for proximate composition. Crude protein, crude lipid and ash were determined using the standard method of the Association of Official Analytical Chemists. Moisture was determined by drying in an oven at $105^{\circ} \mathrm{C}$ for $24 \mathrm{~h}$; crude protein content $(\mathrm{N} \times 6.25)$ was determined by the Kjeldahl method after acid digestion (1030-Auto-analyzer, Tecator); crude lipid was measured by diethyl ether extraction method by a Soxtec System HT (Soxtec System HT6, Tecator); crude ash was examined after combustion in a muffle furnace at $550^{\circ} \mathrm{C}$ for $24 \mathrm{~h}$.

The amino acid composition of all samples was analysed according to the method of Niu et al. ${ }^{(5)}$. Briefly, all samples were submitted to an acid hydrolysis, and then amino acid composition of all samples was analysed using an automatic amino acid analyser (Hitachi 835-50) with a column (Hitachi custom ion exchange resin no. 2619) by Evonik Degussa (China) Co. Ltd.

\section{Activity quantification of antioxidant enzymes}

Fish liver samples were homogenised 1:9, w/v in ice-cold $50 \mathrm{~mm}$ Tris- $\mathrm{HCl}$ buffer solution ( $\mathrm{pH} 7.4$ ) and centrifuged at $12000 \boldsymbol{g}$ for $15 \mathrm{~min}$ at $4^{\circ} \mathrm{C}$, and the cold supernatant was used for the determination of enzymatic activity. Superoxide dismutase (SOD) activity was determined by its ability to inhibit superoxide anion produced by xanthine and xanthine oxidase reaction system ${ }^{(23)}$. Malondialdehyde (MDA) contents were measured by the thiobarbituric acid method according to Miller \& Aust ${ }^{(24)}$. Catalase (CAT) activity was determined by determining the initial amount of hydrogen peroxide decomposition at $240 \mathrm{~nm}^{(25)}$. Antioxidants 
Table 3. Growth performance of Oreochromis niloticus fed experimental diets for $56 \mathrm{~d}$ (Mean values with their standard errors of three replicates)

\begin{tabular}{|c|c|c|c|c|c|c|c|c|c|c|c|c|c|c|}
\hline \multirow[b]{2}{*}{ Diets } & \multicolumn{2}{|c|}{ IBW (g) } & \multicolumn{2}{|c|}{ FBW (g) } & \multicolumn{2}{|c|}{ PWG (\%) } & \multicolumn{2}{|c|}{ SGR (\%/d) } & \multicolumn{2}{|c|}{ Survival (\%) } & \multicolumn{2}{|c|}{ FCR } & \multicolumn{2}{|c|}{ PER } \\
\hline & Mean & SE & Mean & SE & Mean & SE & Mean & SE & Mean & SE & Mean & SE & Mean & SE \\
\hline D1 & $17 \cdot 12$ & 0.02 & $84.46^{a, b}$ & 0.39 & $393^{a}$ & $2 \cdot 81$ & $2 \cdot 85^{\mathrm{a}}$ & 0.01 & $71 \cdot 11$ & $12 \cdot 80$ & 1.44 & 0.02 & $2 \cdot 28$ & 0.03 \\
\hline D2 & $17 \cdot 18$ & 0.06 & $87 \cdot 94^{a, b}$ & 0.38 & $412^{a, b}$ & 4.03 & $2 \cdot 92^{a, b}$ & 0.01 & 95.57 & $1 \cdot 13$ & 1.42 & 0.03 & $2 \cdot 30$ & 0.04 \\
\hline D3 & $17 \cdot 13$ & 0.04 & $92 \cdot 25^{\mathrm{b}}$ & 4.43 & $448^{b}$ & $19 \cdot 60$ & $3.04^{b}$ & 0.06 & $78 \cdot 89$ & 9.09 & $1 \cdot 37$ & 0.03 & $2 \cdot 38$ & 0.05 \\
\hline D4 & $17 \cdot 14$ & 0.06 & $87 \cdot 01^{a, b}$ & $2 \cdot 88$ & $407^{a}$ & $16 \cdot 10$ & $2 \cdot 90^{\mathrm{a}}$ & 0.06 & $80 \cdot 00$ & $15 \cdot 28$ & 1.41 & 0.05 & $2 \cdot 35$ & 0.09 \\
\hline D5 & $17 \cdot 18$ & 0.08 & $86 \cdot 91^{a, b}$ & 2.49 & $406^{a}$ & $13 \cdot 80$ & $2 \cdot 89^{a}$ & 0.05 & 98.89 & $1 \cdot 11$ & $1 \cdot 38$ & 0.03 & $2 \cdot 38$ & 0.06 \\
\hline D6 & $17 \cdot 15$ & 0.08 & $82.96^{a}$ & $1 \cdot 10$ & $384^{a}$ & $5 \cdot 16$ & $2 \cdot 82^{a}$ & 0.02 & $100 \cdot 00$ & 0.00 & 1.45 & 0.02 & $2 \cdot 27$ & 0.04 \\
\hline
\end{tabular}

IBW, initial body weight; FBW, final body weight; PWG, percentage weight gain; SGR, specific growth rate; FCR, feed conversion ratio; PER, protein efficiency ratio.

a,b Mean values in a column with unlike superscript letters were significantly different $(P<0.05)$.

could reduce $\mathrm{Fe}^{3+}$ to $\mathrm{Fe}^{2+}$, the later could form solid clathrate with phenanthroline, and then the total antioxidant capacity (T-AOC) was measured according to the absorption value at $520 \mathrm{~nm}^{(26)}$. The activities of SOD and CAT, T-AOC and the content of MDA were determined by using commercial kits (Nanjing Jiancheng Bioengineering Institute) following the manufacturer's protocol.

\section{DNA extraction and high-throughput sequence analysis}

Total bacterial DNA of gut was extracted directly with the E.Z.N.A. stool DNA Kit (Omega Biotek) according to manufacturer's instructions. The total DNA concentration and quality were measured by a NanoDrop spectrophotometer (ND-2000, Thermo Fisher Scientific) and $1 \%$ agarose gel electrophoresis, respectively. The V4 domain of bacterial 16S rDNA was amplified using the

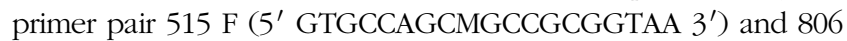
R ( $5^{\prime}$ GGACTACHVGGGTWTCTAAT 3'). The reverse primer contained a 6-bp error-correcting barcode unique to each sample. The PCR reactions contained $100 \mathrm{ng}$ DNA template, $1.5 \mu$ of each forward and reverse primer $(5 \mu \mathrm{M}), 5 \mu \mathrm{l}$ of $2.5 \mathrm{~mm}$ dNTPs, $1 \mu \mathrm{l}$ of Thermococcus kodakaraensis (KOD) polymerase and $5 \mu \mathrm{l}$ of $10 \times \mathrm{KOD}$ buffer. Reaction conditions consisted of an initial $94^{\circ} \mathrm{C}$ for $3 \mathrm{~min}$, followed by thirty-five cycles of $94^{\circ} \mathrm{C}$ for $45 \mathrm{~s}$, $50^{\circ} \mathrm{C}$ for $60 \mathrm{~s}$ and $72^{\circ} \mathrm{C}$ for $90 \mathrm{~s}$, with a final extension of $72^{\circ} \mathrm{C}$ for $10 \mathrm{~min}$. Sequencing was performed using the Illumina HiSeq platform by Biomarker.

Raw reads were de-multiplexed, quality-filtered and analysed using QIIME (version 1.8.0, http://qiime.org/) ${ }^{(27)}$. The low-quality reads were filtered through following rules: Sequences that were shorter than $150 \mathrm{bp}$, average Phred scores below 20, contained primer mismatches, ambiguous bases or mononucleotide repeats longer than $8 \mathrm{bp}^{(28-30)}$. FLASH ${ }^{(31)}$ (version 1.2.7, http://ccb.jhu. edu/software/FLASH/) was used to merge the pairs of reads from the original DNA fragments. Analyse the reads and pick operational taxonomic units (OTU) were done using QLIME software package (http://qiime.org/) and UPARSE pipeline (http://drive5.com/ uparse/). The remaining high-quality sequences were assigned to OTU at $97 \%$ sequence similarity by UCLUST ${ }^{(32)}$ and then classified taxonomically using the Ribosomal Database Project classifier ${ }^{(33)}$. The raw reads were deposited into the NCBI Sequence Read Archive database (Accession Number: SRP190011).

Alpha diversity indices including the Chao1 index (Chao1) and Shannon diversity index were calculated by QIIME (http://qiime. org/scripts/alpha_diversity.html). The Shannon index and Chao1 were used to assess microbiota diversity and evenness. Beta diversity analysis was used to assess the composition variation of microbial communities among samples using UniFrac distance metrics and visualised via principal coordinate analysis ${ }^{(34)}$.

\section{Statistical analysis}

All data are presented as means with their standard errors. Statistical analyses were conducted using SPSS 19.0 (SPSS) and checked for normality and homogeneity of variance before analysis. The growth performance, activity of antioxidant enzymes, proximate composition (diets, whole body and muscle), amino acid composition and alpha diversity were subjected to one-way ANOVA. The differences among treatment means were resolved using Duncan's new multiple range test ${ }^{(35)}$. $P$ values $<0.05$ were considered statistically significant.

\section{Results}

\section{Growth performance}

Significant differences were detected in the growth performance of O. niloticus fed with different diets (Table 3). Results showed that survival rate was in the range of $71-100 \%$ with no significant difference detected among treatments $(P>0 \cdot 05)$. PWG and SGR of $O$. niloticus fed with D3 diet were significantly higher than those fed with D1, D4-D6 diets $(P<0.05)$ but without significant differences with O. niloticus fed the D2 $\operatorname{diet}(P>0 \cdot 05)$. O. niloticus fed with D3 diet showed the highest value of FBW and significantly higher than that of fish fed D6 diet $(P<0 \cdot 05)$, but without significant differences with $O$. niloticus fed the D1, D2, D4 and D5 diets $(P>0.05)$. No significant differences were found in feed conversion ratio and protein efficiency ratio of $O$. niloticus among all diet treatments $(P>0 \cdot 05)$.

\section{Whole body and muscle composition}

The proximate composition of whole body of $O$. niloticus among all diet treatments is shown in Table 4. No significant differences were found in protein, ash and lipid contents of whole body among all diet treatments $(P>0.05)$. Moisture contents of whole body of $O$. niloticus fed with D2 and D5 diets were significantly lower than those fed with D1 diet $(P<0.05)$ but without significant differences with $O$. niloticus fed the D3, D4 and D6 diets $(P>0 \cdot 05)$. 
Table 4. Whole body composition (\% DM) of Oreochromis niloticus fed experimental diets for $56 \mathrm{~d}$ (Mean values with their standard errors of three replicates)

\begin{tabular}{|c|c|c|c|c|c|c|c|c|c|c|c|c|}
\hline \multirow[b]{2}{*}{ Items } & \multicolumn{2}{|c|}{ D1 } & \multicolumn{2}{|c|}{ D2 } & \multicolumn{2}{|c|}{ D3 } & \multicolumn{2}{|c|}{ D4 } & \multicolumn{2}{|c|}{ D5 } & \multicolumn{2}{|c|}{ D6 } \\
\hline & Mean & SE & Mean & SE & Mean & SE & Mean & SE & Mean & SE & Mean & $\mathrm{SE}$ \\
\hline \multicolumn{13}{|l|}{ Whole body } \\
\hline Moisture & $73.52^{b}$ & 0.56 & $71.71^{a}$ & 0.52 & $72 \cdot 25^{a, b}$ & 0.16 & $72 \cdot 45^{a, b}$ & 0.01 & $71.89^{a}$ & 0.35 & $72 \cdot 11^{a, b}$ & 0.63 \\
\hline Protein & 55.05 & 1.73 & 55.59 & 1.01 & 55.56 & 0.83 & 56.56 & 2.47 & $56 \cdot 03$ & 0.65 & 55.971 & 0.63 \\
\hline Lipid & 19.68 & 2.72 & $16 \cdot 13$ & 4.25 & 23.03 & 3.54 & 21.38 & 1.26 & 19.97 & 1.95 & 19.31 & 0.95 \\
\hline Ash & $16 \cdot 49$ & 1.66 & 16.40 & 0.15 & 15.65 & 1.09 & 14.77 & 1.39 & $16 \cdot 10$ & 0.93 & 17.05 & 0.29 \\
\hline
\end{tabular}

a,b Mean values in a row with unlike superscript letters were significantly different $(P<0.05)$.

Table 5. Muscle composition (\% DM) of Oreochromis niloticus fed experimental diets for $56 \mathrm{~d}$ (Mean values with their standard errors of three replicates)

\begin{tabular}{|c|c|c|c|c|c|c|c|c|c|c|c|c|}
\hline \multirow[b]{2}{*}{ Items } & \multicolumn{2}{|c|}{ D1 } & \multicolumn{2}{|c|}{ D2 } & \multicolumn{2}{|c|}{ D3 } & \multicolumn{2}{|c|}{ D4 } & \multicolumn{2}{|c|}{ D5 } & \multicolumn{2}{|c|}{ D6 } \\
\hline & Mean & SE & Mean & SE & Mean & SE & Mean & SE & Mean & SE & Mean & SE \\
\hline \multicolumn{13}{|l|}{ Muscle } \\
\hline Moisture & $76 \cdot 60^{\mathrm{b}}$ & 0.06 & $76 \cdot 37^{a, b}$ & $0 \cdot 15$ & $76 \cdot 67^{b}$ & 0.30 & $75 \cdot 57^{a}$ & 0.53 & $76 \cdot 47^{a, b}$ & 0.24 & $76 \cdot 00^{a, b}$ & 0.25 \\
\hline Protein & 86.53 & 0.07 & 88.00 & 0.21 & 87.57 & 0.12 & $87 \cdot 13$ & 0.95 & 87.03 & 0.35 & $87 \cdot 17$ & 0.15 \\
\hline Lipid & 3.60 & 0.86 & 2.40 & 0.35 & $2 \cdot 73$ & 0.38 & 3.17 & 0.20 & 3.00 & 0.31 & 2.83 & 0.12 \\
\hline Ash & $6 \cdot 73$ & 0.29 & $6 \cdot 27$ & 0.32 & $6 \cdot 67$ & 0.41 & $6 \cdot 20$ & 0.20 & $6 \cdot 10$ & 0.15 & $6 \cdot 13$ & 0.07 \\
\hline
\end{tabular}

a,b Mean values in a row with unlike superscript letters were significantly different $(P<0.05)$.

Table 6. Essential amino acid (EAA) profile (\% DM basis) in the whole body of Oreochromis niloticus fed experimental diets for $56 \mathrm{~d}$ (Mean values with their standard errors of three replicates)

\begin{tabular}{|c|c|c|c|c|c|c|c|c|c|c|c|c|}
\hline \multirow[b]{2}{*}{ EAA } & \multicolumn{2}{|c|}{ D1 } & \multicolumn{2}{|c|}{ D2 } & \multicolumn{2}{|c|}{ D3 } & \multicolumn{2}{|c|}{ D4 } & \multicolumn{2}{|c|}{ D5 } & \multicolumn{2}{|c|}{ D6 } \\
\hline & Mean & SE & Mean & $\mathrm{SE}$ & Mean & SE & Mean & SE & Mean & SE & Mean & $\mathrm{SE}$ \\
\hline Met & $1 \cdot 39^{a}$ & 0.02 & $1.4^{\mathrm{a}}$ & 0.01 & $1.51^{\mathrm{b}}$ & 0.05 & $1.5^{\mathrm{b}}$ & 0.03 & $1 \cdot 44^{a, b}$ & 0.03 & $1.45^{a, b}$ & 0.03 \\
\hline Lys & $4.03^{a}$ & 0.16 & $4 \cdot 15^{\mathrm{a}, \mathrm{b}}$ & 0.12 & $4.49^{b}$ & 0.17 & $4.54^{b}$ & 0.17 & $4 \cdot 16^{a, b}$ & 0.07 & $4 \cdot 38^{a, b}$ & 0.04 \\
\hline Thr & $2 \cdot 39^{a}$ & 0.03 & $2 \cdot 43^{a, b}$ & 0.03 & $2 \cdot 58^{\mathrm{C}}$ & 0.06 & $2 \cdot 54^{\mathrm{b}, \mathrm{c}}$ & 0.03 & $2 \cdot 47^{a, b, c}$ & 0.04 & $2 \cdot 49^{a, b, c}$ & 0.05 \\
\hline Trp & 0.53 & 0.01 & 0.52 & 0.01 & 0.57 & 0.03 & 0.57 & 0.02 & 0.53 & 0.01 & 0.56 & 0.01 \\
\hline Arg & $3 \cdot 22^{a}$ & 0.05 & $3.26^{a}$ & 0.07 & $3.49^{b}$ & 0.04 & $3.53^{b}$ & 0.07 & $3 \cdot 36^{a, b}$ & 0.04 & $3.48^{b}$ & 0.03 \\
\hline Ile & $2 \cdot 30$ & 0.07 & $2 \cdot 32$ & 0.05 & $2 \cdot 47$ & 0.07 & 2.47 & 0.08 & $2 \cdot 32$ & 0.04 & 2.42 & 0.01 \\
\hline Leu & $3.77^{a}$ & 0.09 & $3 \cdot 83^{a, b}$ & 0.07 & $4 \cdot 10^{b}$ & 0.09 & $4.08^{b}$ & 0.14 & $3 \cdot 83^{a, b}$ & 0.06 & $3.94^{a, b}$ & 0.01 \\
\hline Val & $2 \cdot 65$ & 0.04 & $2 \cdot 67$ & 0.08 & $2 \cdot 82$ & 0.12 & 2.82 & 0.04 & 2.75 & 0.08 & 2.78 & 0.06 \\
\hline His & $1 \cdot 3^{a}$ & 0.01 & $1 \cdot 36^{a, b}$ & 0.02 & $1.44^{b}$ & 0.02 & $1.45^{\mathrm{b}}$ & 0.03 & $1 \cdot 36^{a, b}$ & 0.05 & $1 \cdot 39^{a, b}$ & 0.03 \\
\hline Phe & $2 \cdot 22^{a}$ & 0.02 & $2 \cdot 33^{a, b}$ & 0.06 & $2 \cdot 45^{\mathrm{b}}$ & 0.04 & $2 \cdot 43^{b}$ & 0.11 & $2 \cdot 27^{a, b}$ & 0.05 & $2 \cdot 36^{a, b}$ & 0.03 \\
\hline$\Sigma \mathrm{EAA}$ & $23 \cdot 79^{a}$ & 0.44 & $24 \cdot 27^{a}$ & 0.22 & $25 \cdot 92^{b}$ & 0.58 & $25.94^{b}$ & 0.69 & $24 \cdot 48^{a, b}$ & 0.45 & $25 \cdot 25^{a, b}$ & 0.14 \\
\hline
\end{tabular}

a,b,c Mean values in a row with unlike superscript letters were significantly different $(P<0.05)$.

The proximate composition of muscle of $O$. niloticus among all diet treatments is shown in Table 5. No significant differences were found in protein, ash and lipid contents of muscle among all diet treatments $(P>0 \cdot 05)$. Moisture contents of muscle of $O$. niloticus fed with D4 diets were significantly lower than those fed with D1 and D3 diets $(P<0.05)$ but without significant differences with $O$. niloticus fed the D2, D5 and D6 diets $(P>0.05)$.

\section{Whole body essential amino acid profile}

The EAA composition of whole body of $O$. niloticus among all diet treatments is shown in Table 6. No significant differences were found in tryptophan, isoleucine and valine levels in whole body of $O$. niloticus among the dietary treatments $(P>0.05)$. There were significant differences in the composition of other EAA in O. niloticus between the experimental groups. Met level in whole body of O. niloticus fed with D3 and D4 diets was significantly higher than those fed with D1 and D2 diets $(P<0.05)$ but without significant difference with $O$. niloticus fed the D5 and D6 diets $(P>0 \cdot 05)$. Arginine level in whole body of O. niloticus fed with D3, D4 and D6 diets was significantly higher than those fed with D1 and D2 diets $(P<0.05)$ but without significant difference with $O$. niloticus fed the D5 diet $(P>0.05)$. Lysine, histidine, leucine and phenylalanine levels of $O$. niloticus fed with D3 and D4 diets were significantly higher than those fed with D1 diet $(P<0.05)$ but without significant difference with $O$. niloticus fed the D2, D5 and D6 diets $(P>0.05)$. Threonine level of $O$. niloticus fed with $\mathrm{D} 3$ diet was significantly higher than those fed with D1 and D2 diets $(P<0.05)$ but without significant difference with $O$. niloticus fed the D4-D6 diets $(P>0.05)$. Total EAA content in whole body of $O$. niloticus fed with D3 and D4 diets was significantly higher than those fed with D1 and D2 diets $(P<0.05)$ but without significant difference with $O$. niloticus fed the D5 and D6 diets $(P>0 \cdot 05)$. 
Table 7. Effect of experimental diets on antioxidant parameters (catalase (CAT), U/mg protein; superoxide dismutase (SOD), U/mg protein; malondialdehyde (MDA), $\mathrm{nmol} / \mathrm{mg}$ protein; total antioxidant capacity (T-AOC), $\mathrm{mg}$ protein/ $\mathrm{ml}$ ) of Oreochromis niloticus at the end of the trial (56 d) (Mean values with their standard errors of three replicates)

\begin{tabular}{|c|c|c|c|c|c|c|c|c|c|c|c|c|}
\hline & \multicolumn{2}{|c|}{ D1 } & \multicolumn{2}{|c|}{ D2 } & \multicolumn{2}{|c|}{ D3 } & \multicolumn{2}{|c|}{ D4 } & \multicolumn{2}{|c|}{ D5 } & \multicolumn{2}{|c|}{ D6 } \\
\hline & Mean & SE & Mean & $\mathrm{SE}$ & Mean & $\mathrm{SE}$ & Mean & SE & Mean & SE & Mean & $\mathrm{SE}$ \\
\hline CAT & 5.58 & 1.11 & 5.56 & 0.94 & $6 \cdot 80$ & 0.72 & 4.74 & 0.95 & 5.68 & 0.64 & 6.86 & 0.32 \\
\hline SOD & $110 \cdot 72^{a, b}$ & 3.92 & $116 \cdot 47^{b}$ & 9.68 & $103 \cdot 85^{a, b}$ & $3 \cdot 14$ & $92 \cdot 85^{a}$ & 4.49 & $94.56^{a}$ & 8.03 & $105 \cdot 88^{a, b}$ & 5.23 \\
\hline MDA & $1 \cdot 25^{a, b}$ & 0.07 & $1.40^{\mathrm{b}}$ & 0.07 & $1 \cdot 21^{\mathrm{a}, \mathrm{b}}$ & 0.17 & $1.05^{a, b}$ & 0.1 & $0.94^{a}$ & 0.09 & $0.95^{a}$ & 0.14 \\
\hline T-AOC & $5 \cdot 68^{a, b}$ & 1.50 & $4.05^{a}$ & 0.26 & $13 \cdot 30^{d}$ & 1.71 & $6 \cdot 39^{a, b}$ & 0.06 & $9 \cdot 92^{\mathrm{C}}$ & 0.94 & $8.08^{b, c}$ & 0.13 \\
\hline
\end{tabular}

a,b,c,d Mean values in a row with unlike superscript letters were significantly different $(P<0.05)$.

Table 8. Diversity index of gut bacteria of juvenile Oreochromis niloticus fed the six experimental diets for 8 weeks based on V4 sequences* (Mean values with their standard errors)

\begin{tabular}{|c|c|c|c|c|c|c|c|c|c|c|c|c|}
\hline \multirow[b]{2}{*}{ Items } & \multicolumn{2}{|c|}{ D1 } & \multicolumn{2}{|c|}{$\mathrm{D} 2$} & \multicolumn{2}{|c|}{ D3 } & \multicolumn{2}{|c|}{ D4 } & \multicolumn{2}{|c|}{ D5 } & \multicolumn{2}{|c|}{ D6 } \\
\hline & Mean & SE & Mean & SE & Mean & SE & Mean & SE & Mean & SE & Mean & SE \\
\hline OTU & \multicolumn{2}{|c|}{456} & \multicolumn{2}{|c|}{431} & \multicolumn{2}{|c|}{454} & \multicolumn{2}{|c|}{456} & \multicolumn{2}{|c|}{435} & \multicolumn{2}{|c|}{431} \\
\hline Chao1 & $443.9^{c}$ & $5 \cdot 86$ & $412 \cdot 1^{a, b}$ & $6 \cdot 7$ & $429 \cdot 73^{b, c}$ & 1.91 & $430 \cdot 63^{b, c}$ & $10 \cdot 44$ & $413 \cdot 38^{a, b}$ & $5 \cdot 82$ & $403 \cdot 11^{a}$ & 4.42 \\
\hline Shannon & $2 \cdot 2^{b}$ & 0.01 & $2.07^{a}$ & 0.01 & $2 \cdot 44^{\mathrm{C}}$ & 0.02 & $2 \cdot 21^{b}$ & 0.06 & $2 \cdot 11^{\mathrm{a}, \mathrm{b}}$ & 0.03 & $2 \cdot 18^{a, b}$ & 0.04 \\
\hline
\end{tabular}

OTU, operational taxonomic units; Chao1, Chao 1 index; Shannon, Shannon diversity index.

$a, b, c$ Mean values in a row with unlike superscript letters were significantly different $(P<0.05)$.

${ }^{*} n 4$ for OTU and $n 10$ for Chao1 and Shannon.

\section{Antioxidant capacity}

Antioxidant capacity of $O$. niloticus is shown in Table 7. T-AOC was significantly higher in O. niloticus fed with D3 diet, than in O. niloticus fed with D1, D2 and D4-D6 diets $(P<0 \cdot 05)$. The SOD activity and MDA content of $O$. niloticus fed with D2-D6 diets had no significant difference compared with $O$. niloticus fed the D1 diet $(P>0.05)$. No significant differences were found in CAT activity among all diet treatments $(P>0 \cdot 05)$.

\section{Composition of intestinal microbiota}

A total of 5628254 high-quality sequencing reads were obtained, and they were clustered into OTU of $\geq 97 \%$ identity. The number of OTU detected in each sample ranged from 431 to 456 (Table 8). Samples from the six diet groups were well separated. At the phylum level, Fusobacteria (53.44-58.82\%) was the dominant phylum in all the six dietary treatments and then followed by Bacteroidetes (16.75-30.99\%) (Fig. 1). Bacteroidetes in the D3 diet treatment was significantly lower than those from other diets treatments; however, Firmicutes in the D3 diet treatment was significantly higher than those from other diets treatments $(P<0.05)$. At the family level, Fusobacteriaceae (53.33-58.69\%) was the dominant family in all six diets treatments, and then followed by Porphyromonadaceae (16.71-30.99\%) (Fig. 2). Porphyromonadaceae in the D3 diet treatment was significantly lower than those from other diets treatments; however, Clostridiaceae_1 in the D3 diet treatment was significantly higher than those from other diets treatments; moreover, Rhodobacteraceae from D3-D6 diets treatments was significantly higher than those from D1 and D2 diets treatments $(P<0.05)$. At the genus level, Cetobacterium (55.50-58.22\%) was the dominant genus in all the six diets treatments and then followed by
uncultured_bacterium_f_Porphyromonadaceae (17.75-20.74\%) (Fig. 3). No significant difference at genus level was found in all the six dietary treatments $(P>0 \cdot 05)$.

\section{Diversity analysis of intestinal microbiota}

The alpha diversity metrics were calculated from the rarefaction curves at OTU level for each experimental feed. Chao1, Shannon index and relative abundance of microbial community are shown in Table 8 and Fig. 4. There were significant differences in Chao1 and Shannon index among the experimental groups (Table $8, P<0 \cdot 05)$. Chao1 in the D1 diet treatment was significantly higher than those from D2, D5 and D6 diets $(P<0.05)$ but without significant difference from D3 and D4 diets $(P>0.05)$. Shannon index in the D3 diet treatment was significantly higher than those from other diets treatments $(P<0 \cdot 05)$. The results indicated that diversity of the microbial community in the D3 diet treatment was highest. Beta diversity was demonstrated by principal coordinate analysis. All samples showed in principal coordinate analysis using unweighted UniFrac distances were regularly distributed according to different treatment groups (Fig. 5). Principal coordinate analysis showed separated clustering of the control group and the MetMet supplementation groups, indicating that supplementation of Met-Met in feed could significantly alter the structure of intestinal microbiota.

\section{Discussion}

To maintain the sustainable development of O. niloticus aquaculture, it is necessary to optimise the feed products used. A proper diet is essential to improve the growth performance and survival of the fish and to ensure that a high-quality 


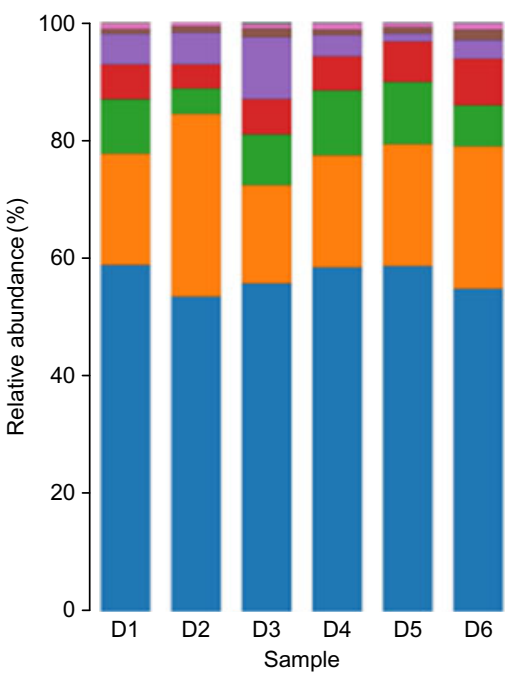

\begin{tabular}{|c|c|c|c|c|c|c|c|c|c|c|c|c|}
\hline & \multicolumn{2}{|c|}{ D1 (\%) } & \multicolumn{2}{|c|}{$\mathrm{D} 2(\%)$} & \multicolumn{2}{|c|}{ D3 (\%) } & \multicolumn{2}{|c|}{ D4 (\%) } & \multicolumn{2}{|c|}{ D5 (\%) } & \multicolumn{2}{|c|}{$\mathrm{D} 6(\%)$} \\
\hline & Mean & SE & Mean & SE & Mean & SE & Mean & SE & Mean & SE & Mean & SE \\
\hline Fusobacteria & $58 \cdot 82^{b}$ & 0.47 & $53 \cdot 44^{a}$ & 0.36 & $55 \cdot 7^{a, b}$ & 0.42 & $58 \cdot 42^{b}$ & $1 \cdot 64$ & $58 \cdot 81^{b}$ & 0.97 & $54 \cdot 51^{a}$ & $1 \cdot 33$ \\
\hline Bacteroidetes & $18 \cdot 93^{b}$ & $0 \cdot 13$ & $30 \cdot 99^{e}$ & 0.33 & $16 \cdot 75^{a}$ & 0.33 & $19 \cdot 01^{b}$ & 0.65 & $20 \cdot 59^{c}$ & 0.42 & $24 \cdot 26^{d}$ & 0.55 \\
\hline Proteobacteria & $9 \cdot 19^{c, d}$ & $0 \cdot 11$ & $4 \cdot 28^{a}$ & $0 \cdot 12$ & $8 \cdot 63^{c}$ & $0 \cdot 15$ & $11 \cdot 15^{\mathrm{e}}$ & $0 \cdot 77$ & $10 \cdot 42^{\mathrm{d}, \mathrm{e}}$ & 0.98 & $6 \cdot 88^{b}$ & 0.33 \\
\hline Verrucomicrobia & $5 \cdot 93^{b}$ & $0 \cdot 12$ & $4 \cdot 12^{a}$ & 0.41 & $5 \cdot 94^{b}$ & $0 \cdot 14$ & $5 \cdot 72^{\mathrm{b}}$ & 0.54 & $6 \cdot 87^{\mathrm{b}, \mathrm{c}}$ & 0.43 & $8.05^{c}$ & $1 \cdot 00$ \\
\hline Firmicutes & $5 \cdot 20^{c}$ & $0 \cdot 12$ & $5 \cdot 46^{c}$ & $0 \cdot 16$ & $10 \cdot 49^{d}$ & 0.36 & $3 \cdot 55^{b}$ & $0 \cdot 28$ & $1 \cdot 46^{a}$ & $0 \cdot 19$ & $3 \cdot 18^{b}$ & $0 \cdot 21$ \\
\hline Actinobacteria & $0.83^{a}$ & 0.04 & $1 \cdot 03^{a}$ & 0.05 & $1.49^{a, b}$ & 0.08 & $0.91^{a}$ & 0.08 & $0.98^{a}$ & $0 \cdot 16$ & $1 \cdot 83^{b}$ & 0.45 \\
\hline
\end{tabular}

Fig. 1. (Colour online) Relative abundance of bacterial phyla in the six dietary groups. $(\square)$, Others; $(\square)$, unassigned; $(\square)$, Chloroflexi; $(\square)$, Planctomycetes; $(\square)$, Cyanobacteria; $(\square)$, Actinobacteria; $(\square)$, Firmicutes; $(\square)$, Verrucomicrobia; $(\square)$, Proteobacteria; $(\square)$, Bacteroidetes; $(\square)$, Fusobacteria. Values are means with their standard errors $(n 4)$. a,b,c,d,e Mean values in a row with unlike superscript letters were significantly different $(P<0.05)$.

and sustainable product is available to consumer. Met-Met, as novel nutritional supplements for aquatic and terrestrial animals, has attracted much attention in recent years. Reports concerning aquatic and terrestrial animals have indicated that the dietary supplementation with Met-Met can improve the growth performance of organisms ${ }^{(5,17,18,36)}$. Su et al. indicated that dietary Met-Met supplementation increased PWG, SGR and feed efficiency in $C$. idella ${ }^{(18)}$. Dietary Met-Met supplementation increased PWG and SGR was also reported in Pagrus major by Mamauag et al. ${ }^{(37)}$. Niu et al. demonstrated that supplementation of Met-Met in L. vannamei feed can improve growth performance (PWG and SGR) and efficiency of feed utilisation (protein efficiency ratio and feed efficiency) ${ }^{(5)}$. Similar results were also reported in L. vannamei by Xie $e t a l{ }^{(17)}$. The results from the present study are similar to those described above. The present study indicated that the optimal Met-Met supplementation remarkably increased the PWG and SGR of O. niloticus. The results demonstrated that Met in dipeptide form can be efficiently absorbed and utilised by $O$. niloticus. Generally, the lower the dietary Met content, the worse the growth performance of fish. However, our results showed that the growth performance of $O$. niloticus was not only improved when the dietary Met level was higher than $0.61 \%$ but no adverse effect could be detected in fish fed higher levels of Met. Espe et al. obtained different results in their research ${ }^{(38)}$. Their research indicated that dietary Met levels exceeding the requirements of Atlantic salmon have a negative impact on feed intake, growth performance and survival. Above results do not contradict the idea that supplementation of Met-Met in O. niloticus feed can improve growth performance. The difference in the effect of Met on the growth performance of aquatic animals may be related to the form and processing technology of Met and experimental conditions (supplementary level, species and experimental period). Since due to the growth results, the authors conclude the optimal proportion of Met was $0.61 \%$ and the addition of Met-Met was $0.15 \%$ in O. niloticus

The EAA composition of whole body of O. niloticus was affected by the different dietary treatments. The present study indicated that dietary supplementation of Met-Met significantly increased the levels of Met, lysine, threonine, arginine, leucine, histidine, phenylalanine and total EAA in the whole body of O. niloticus. Similar results were also reported in L. vannamei by Niu et al. ${ }^{(5)}$ and Xie et $a l .{ }^{(17)}$. Niu et al. indicated that the optimal Met-Met supplementation significantly increased the content of total EAA in L. vannamei ${ }^{(5)}$. Nevertheless, Boonyoung et al. 


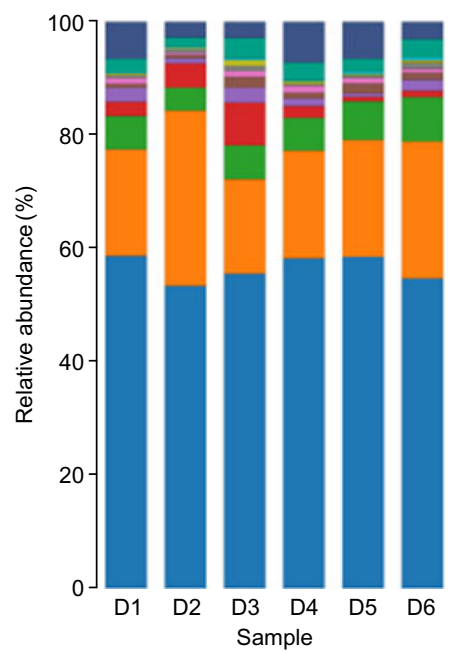

\begin{tabular}{|c|c|c|c|c|c|c|c|c|c|c|c|c|}
\hline & \multicolumn{2}{|c|}{$\mathrm{D} 1(\%)$} & \multicolumn{2}{|c|}{$\mathrm{D} 2(\%)$} & \multicolumn{2}{|c|}{ D3(\%) } & \multicolumn{2}{|c|}{$\mathrm{D} 4(\%)$} & \multicolumn{2}{|c|}{ D5(\%) } & \multicolumn{2}{|c|}{ D6(\%) } \\
\hline & Mean & SE & Mean & SE & Mean & SE & Mean & SE & Mean & SE & Mean & SE \\
\hline Fusobacteriaceae & $58 \cdot 69^{b}$ & 0.47 & $53 \cdot 33^{a}$ & 0.35 & $55 \cdot 59^{a, b}$ & 0.42 & $58 \cdot 28^{b}$ & 1.63 & $58 \cdot 69^{b}$ & 0.97 & $54 \cdot 41^{a}$ & $1 \cdot 32$ \\
\hline Porphyromonadaceae & $18 \cdot 82^{b}$ & $0 \cdot 13$ & $30.99^{e}$ & 0.33 & $16 \cdot 71^{\mathrm{a}}$ & 0.34 & $18 \cdot 99^{b}$ & 0.66 & $20 \cdot 59^{c}$ & 0.42 & $24 \cdot 26^{d}$ & 0.55 \\
\hline Verrucomicrobiaceae & $5 \cdot 92^{\mathrm{b}}$ & $0 \cdot 11$ & $4 \cdot 11^{\mathrm{a}}$ & 0.41 & $5 \cdot 93^{b}$ & $0 \cdot 14$ & $5 \cdot 70^{\mathrm{b}}$ & 0.54 & $6 \cdot 86^{b, c}$ & 0.43 & $8 \cdot 03^{c}$ & $1 \cdot 00$ \\
\hline Clostridiaceae_1 & $2 \cdot 53^{c}$ & 0.04 & $4 \cdot 29^{d}$ & $0 \cdot 14$ & $7 \cdot 58^{\mathrm{e}}$ & $0 \cdot 18$ & $2 \cdot 09^{b}$ & $0 \cdot 16$ & $0.83^{a}$ & $0 \cdot 11$ & $1 \cdot 11^{\mathrm{a}}$ & 0.05 \\
\hline Peptostreptococcaceae & $2 \cdot 46^{c}$ & 0.07 & $0.89^{a, b}$ & 0.01 & $2 \cdot 57^{\mathrm{c}}$ & $0 \cdot 21$ & $1 \cdot 30^{\mathrm{b}}$ & $0 \cdot 17$ & $0 \cdot 56^{a}$ & 0.08 & $1.97^{\mathrm{C}}$ & 0.24 \\
\hline Rhodobacteraceae & $0.67^{a}$ & 0.02 & $0 \cdot 56^{a}$ & 0.01 & $1.90^{c}$ & 0.07 & $1 \cdot 08^{b}$ & $0 \cdot 19$ & $1 \cdot 85^{a}$ & 0.23 & $1 \cdot 25^{\mathrm{b}}$ & 0.09 \\
\hline
\end{tabular}

Fig. 2. (Colour online) Relative abundance of bacterial families in the six dietary groups. ( $\square$ ), Unclassified; ( $\square$ ), others; ( $\square$ ), MNG7; ( $)$, Enterobacteriaceae; ( $\square$ ),

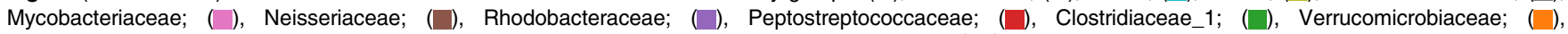
Porphyromonadaceae; $(\square)$, Fusobacteriaceae. Values are means with their standard errors $\left(n\right.$ 4). ${ }^{a, b, c, d, e}$ Mean values in a row with unlike superscript letters were significantly different $(P<0.05)$.

indicated that there was no significant difference in the EAA composition of whole body of Oncorbynchus mykiss fed the diets with or without MHA supplementation ${ }^{(39)}$. Supplementation of coated Met did not show remarkable difference in the amino acid composition of whole body of Marsupenaeus japonicus which was also reported by Alam et $a l^{(40)}$. The present studies have shown that the effects of Met on amino acid composition of aquatic animals are not entirely consistent. This difference may be related to the form and processing technology of Met, proportion of amino acid and experimental conditions (supplementary level, feeding regimen, species and experimental period). There is no doubt that Met-Met, a new Met product, can be well absorbed and utilised by $O$. niloticus. Dietary Met-Met supplementation can promote the absorption and utilisation of amino acids (Met, lysine, threonine, arginine, leucine, histidine and phenylalanine), which may contribute to faster growth in O. niloticus

Fish is the main source of animal protein and micronutrients in developing countries ${ }^{(41)}$. It is essential to provide adequate dietary amino acids for human health, growth, development and survival ${ }^{(42)}$. Amino acids play an important role in maintaining normal physiological function and nutritional status of the body ${ }^{(43)}$. For example, arginine plays a regulatory role in immune function, wound healing, hormone secretion, insulin sensitivity, protein synthesis and endothelial function ${ }^{(42,44)}$; Met can regulate the metabolic process, innate immune system and digestive function ${ }^{(45)}$. Therefore, human consumption of $O$. niloticus rich in EAA is conducive to growth and health. Adding Met-Met to aquatic animal feed can improve the quality of aquatic products.

Oxidative burst is an important defence mechanism, but it can produce harmful substances, such as superoxide anion, hydrogen peroxide and hydroxyl radicals ${ }^{(46)}$. To reduce oxidative stress or damage caused by reactive oxygen species, cells have developed a set of antioxidant defence systems involving antioxidant enzymes. SOD and CAT are the main antioxidant enzymes, and T-AOC can evaluate the antioxidant ability of organisms by non-enzymatic or enzymatic components ${ }^{(47)}$. MDA is a product of lipid peroxidation, which mainly evaluates the damage degree of cell structure and function by its content in serum or tissue ${ }^{(48)}$. In the present study, the T-AOC was increased in fed the diet with Met-Met supplementation; however, the SOD and CAT activity and MDA content were no significant difference in fed the diet with or without Met-Met 


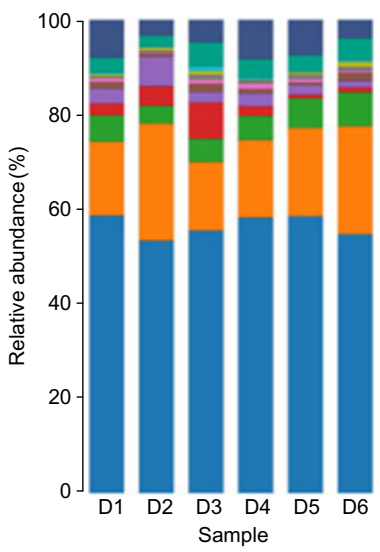

\begin{tabular}{|c|c|c|c|c|c|c|c|c|c|c|c|c|}
\hline & \multicolumn{2}{|c|}{$\mathrm{D} 1(\%)$} & \multicolumn{2}{|c|}{$\mathrm{D} 2(\%)$} & \multicolumn{2}{|c|}{ D3 (\%) } & \multicolumn{2}{|c|}{ D4 (\%) } & \multicolumn{2}{|c|}{ D5 (\%) } & \multicolumn{2}{|c|}{ D6 (\%) } \\
\hline & Mean & $\mathrm{SE}$ & Mean & $\mathrm{SE}$ & Mean & SE & Mean & SE & Mean & $\mathrm{SE}$ & Mean & SE \\
\hline Cetobacterium & $55 \cdot 80$ & $1 \cdot 31$ & $56 \cdot 03$ & $1 \cdot 60$ & $58 \cdot 22$ & $2 \cdot 02$ & $55 \cdot 80$ & $1 \cdot 11$ & $56 \cdot 14$ & $1 \cdot 79$ & $57 \cdot 29$ & $0 \cdot 82$ \\
\hline $\begin{array}{l}\text { uncultured_bacterium_f } \\
\text { Porphyromonadaceae }\end{array}$ & $17 \cdot 75$ & $2 \cdot 26$ & $20 \cdot 13$ & $2 \cdot 04$ & $17 \cdot 86$ & $2 \cdot 28$ & $17 \cdot 88$ & $2 \cdot 23$ & $20 \cdot 74$ & $2 \cdot 24$ & $18 \cdot 07$ & 1.64 \\
\hline Akkermansia & $5 \cdot 13$ & $0 \cdot 29$ & 5.99 & 0.94 & $5 \cdot 77$ & 0.95 & $5 \cdot 10$ & 0.33 & $5 \cdot 80$ & $1 \cdot 18$ & $5 \cdot 23$ & $0 \cdot 20$ \\
\hline $\begin{array}{l}\text { Clostridium_sensu_ } \\
\text { stricto_1 }\end{array}$ & $4 \cdot 05$ & $1 \cdot 23$ & $2 \cdot 14$ & 0.66 & $2 \cdot 92$ & $1 \cdot 46$ & $4 \cdot 11$ & $1 \cdot 33$ & $2 \cdot 19$ & 0.80 & $2 \cdot 78$ & $1 \cdot 70$ \\
\hline Porphyromonas & $3 \cdot 64$ & $0 \cdot 77$ & $3 \cdot 15$ & $1 \cdot 15$ & 1.95 & 0.33 & $3 \cdot 61$ & 0.87 & $3 \cdot 30$ & $1 \cdot 17$ & $2 \cdot 14$ & $0 \cdot 20$ \\
\hline Peptoclostridium & 1.09 & $0 \cdot 29$ & 1.04 & 0.28 & $1 \cdot 05$ & 0.23 & $1 \cdot 10$ & 0.20 & $0 \cdot 87$ & 0.24 & $1 \cdot 41$ & 0.47 \\
\hline
\end{tabular}

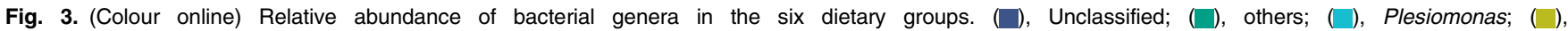

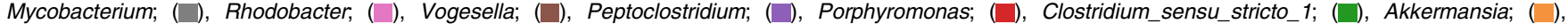
uncultured_bacterium_f_Porphyromonadaceae; $(\square)$, Cetobacterium. Values are means with their standard errors $(n 4)$.

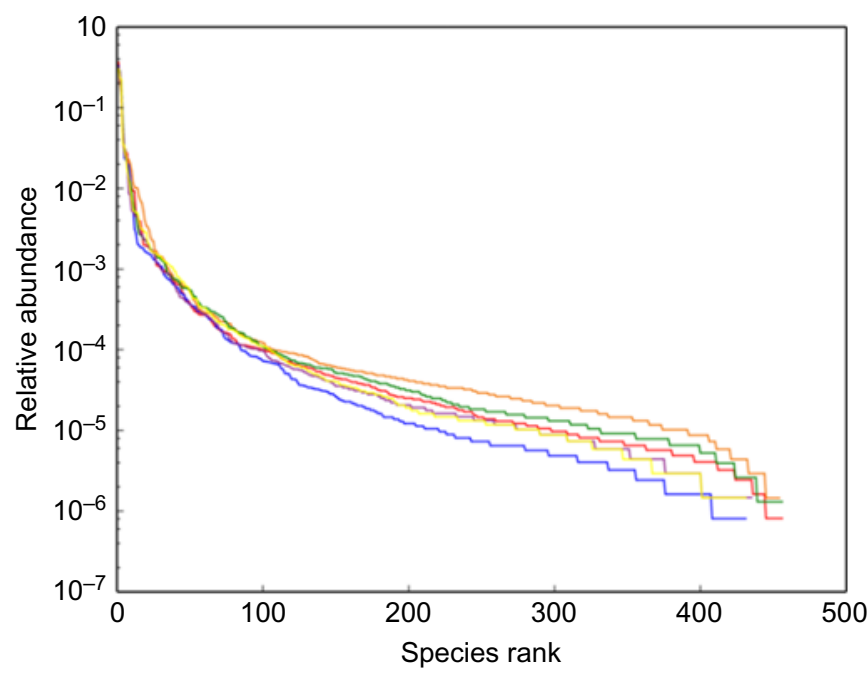

Fig. 4. (Colour online) Relative abundance of microbial community. $(-)$, D1; $(-)$, D3; $(-)$, D4; $(-)$, D5; ( ), D6; (-), D2.

supplementation. The present results indicated that dietary MetMet supplementation did not cause damage to hepatocytes and improved antioxidant capacity of $O$. niloticus. Feng et al. indicated that dietary MHA supplementation increased the SOD and CAT activity and reduced the MDA content in the liver of Cyprinus carpio ${ }^{(49)}$. Elmada et al. demonstrated that dietary supplementation of Met increased the SOD activity and the MDA content in serum of Pelteobagrus fulvidraco; however, the CAT activity was not significantly affected by the dietary Met levels ${ }^{(50)}$. The above results showed that the effects of different Met forms on antioxidant enzymes activities in different species and tissues were not entirely consistent. This may be due to the different tolerance of different species to Met. These results do not contradict the idea that dietary supplementation of MetMet or Met can improve antioxidant ability. The results also indicated that Met plays an important role in regulating immune function in aquatic animals.

The effect of Met-Met supplementation on intestinal microbiota of $O$. niloticus was first reported in the present study. The present results indicated that Fusobacteria was the dominant phylum in O. niloticus, followed by Bacteroidetes, Proteobacteria, Verrucomicrobia, Firmicutes and Actinobacteria. However, Adeoye et al. showed that Fusobacteria was the dominant phylum in $\mathrm{O}$. niloticus, followed by Proteobacteria and Firmicutes $^{(51)}$. In our study, the second dominant phylum was Bacteroidetes. Our results are different from those of Adeoye et $a l .{ }^{(51)}$. The main reason for the difference in results may be attributed to the difference in feed formula. It is well known that the most important contribution of Bacteroidetes is the 


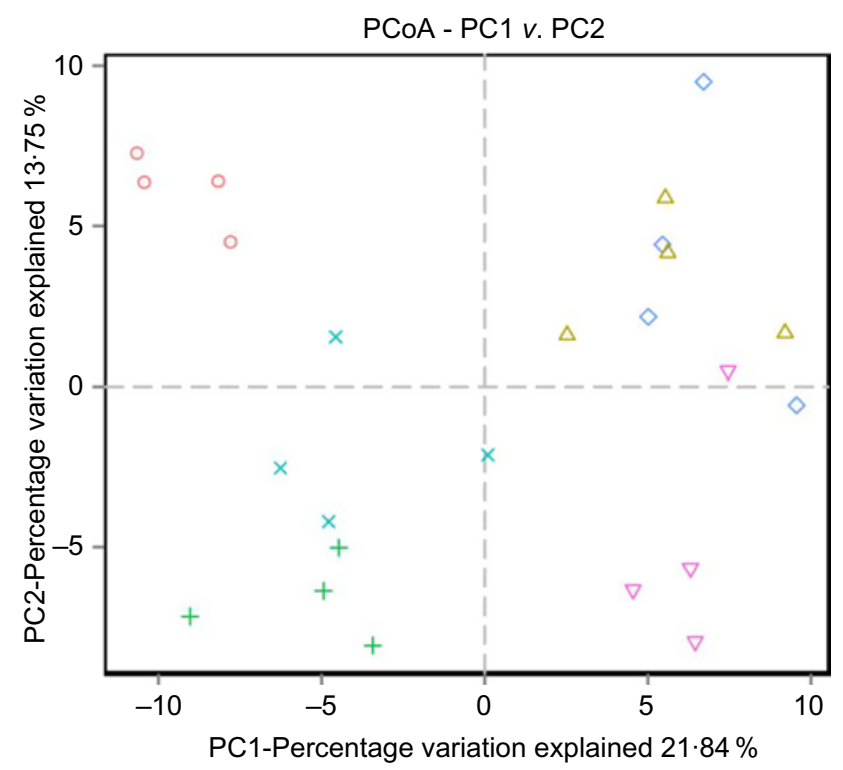

Fig. 5. (Colour online) Unweighted principal coordinate analysis (PCoA) of UniFrac distances. (०), D1; ( ), D2; (+), D3; (×), D4; ( $)$, D5; ( $)$, D6.

degradation of dietary fibre in human ${ }^{(52)}$. In our feed formula, the feed protein was all derived from plant protein and no fishmeal was used as a feed protein source. Therefore, the dominance of Bacteroidetes may be related to the high fibre content in our feed.

The structure of intestinal microbiota is an extremely complex collective, which has proved to have a great positive impact on host immunity, such as improving innate immune response, preventing overgrowth of pathogenic micro-organisms and metabolising exogenous substances ${ }^{(53-55)}$. In the present study, alpha diversity (Chao1 and Shannon index) which reflects the microbiota richness and diversity evidence was significantly affected in the six experimental diets. The results indicated that dietary supplementation of Met-Met leads to alterations in the gut microbiota in O. niloticus, especially in D3 diet treatment. O. niloticus fed with D3 diet showed the lowest abundance of Bacteroidetes and the highest abundance of Firmicutes. Bacteroidetes and Firmicutes occupy different functional niches in the intestinal ecosystem, and their differences in relative proportions can lead to huge functional differences ${ }^{(56)}$. Mulder et al. indicated that there was a strong negative correlation between the abundance of Firmicutes and pathogenic bacterial populations in the intestine ${ }^{(57)}$. Mariat et al. also demonstrated that lower Firmicutes:Bacteroidetes ratios in the intestine could increase the sensitivity of infants and the elderly to pathogens ${ }^{(58)}$. In the present study, dietary supplementation of $0 \cdot 15 \%$ Met-Met could significantly increase Firmicutes:Bacteroidetes ratios, so we infer that Met-Met supplementation could contribute to improving the resistance of $\mathrm{O}$. niloticus to pathogens. The predominance of Firmicutes in intestinal microflora was also considered a characteristic of obese people ${ }^{(59)}$. Li et al. indicated that Firmicutes domination in high growth performance group was likely beneficial to the growth of tilapia ${ }^{(60)}$. We also got similar results. High growth performance was obtained in O. niloticus fed D3 diet; meanwhile Firmicutes was dominant in intestinal microflora.

\section{Conclusion}

In the present study, we evaluated the effects of Met-Met, a new source of Met product, on growth performance, antioxidant capacity and intestinal microbiota of $O$. niloticus for the first time. Dietary Met-Met supplementation increased growth performance, antioxidant ability and the content of EAA in O. niloticus. Meanwhile, Met-Met supplementation alters intestinal microbiota composition in O. niloticus. Adding 0.15\% Met-Met to feed can improve the diversity of intestinal microbiota of O. niloticus. The optimal content of dietary Met was found to be $0.61 \%$ with the supplementation of $0.15 \%$ Met-Met based on the optimal growth performance and antioxidant ability of grower-phase O. niloticus.

\section{Ethical Statement}

All the experiments were conducted in accordance with the recommendations in the Guide for the Care and Use of Laboratory Animals of the National Institutes of Health. The study protocol and all experimental procedures were approved by Experimental Animal Ethics Committee of Sun Yat-sen University.

\section{Acknowledgements}

The authors thank for the funding of the Project from Evonik Degussa (China) Co., Ltd (03 87 16004_1), Project of National Natural Science Foundation of China (31872580), Project of Marine Fishery Science and Technology of Guangdong Province (A201601C11, GDME-2018C012), Natural Science Foundation of Guangdong Province (2017A030313195), Project of Science and Technology of Guangzhou City (201803020006) and Modern Agriculture and Marine Biological Industry of ShenZhen (20170428140437749).

The authors thank the participants who gave their time to the trial.

J. N., Y.-J. L., L.-X. T., J.-Y. H. and K. M. designed the study. T.-Y. G., W.-Z., J.-J. X. and S.-Y. L. carried out the rearing work. T.-Y. G. and W.-Z. analysed the results and wrote the paper with contributions from the other authors.

J.-Y. H. was employed by company Evonik Degussa (China) Co., Ltd. Guangzhou Branch. K. M. was employed by company Evonik Nutrition and Care GmbH. The authors declare that the present study received funding from Evonik Nutrition and Care $\mathrm{GmbH}$. The sponsor partcipated in the design of the experiment and editing the manuscript. All other authors declare no conflicts of interests.

\section{References}

1. Boonanuntanasarn S, Nakharuthai C, Schrama D, et al. (2019) Effects of dietary lipid sources on hepatic nutritive contents, fatty acid composition and proteome of Nile tilapia (Oreochromis niloticus). J Proteomics 192, 208-222.

2. Beal CM, Gerber LN, Thongrod S, et al. (2018) Marine microalgae commercial production improves sustainability of global fisheries and aquaculture. Sci Rep $\mathbf{8}, 15064$.

3. FAO (2018) The State of World Fisheries and Aquaculture 2018. Rome: FAO. 
4. Hardy RW (2010) Utilization of plant proteins in fish diets: effects of global demand and supplies of fishmeal. Aquac Res 41, 770-776.

5. Niu J, Lemme A, He J-Y, et al. (2018) Assessing the bioavailability of the Novel Met-Met product (AQUAVI ${ }^{\circledR}$ Met-Met) compared to DL-methionine (DL-Met) in white shrimp (Litopenaeus vannamei). Aquaculture 484, 322-332.

6. Belghit I, Skiba-Cassy S, Geurden I, et al. (2014) Dietary methionine availability affects the main factors involved in muscle protein turnover in rainbow trout (Oncorbynchus mykiss). BrJ Nutr 112, 493-503.

7. Gao Z, Wang X, Tan C, et al. (2019) Effect of dietary methionine levels on growth performance, amino acid metabolism and intestinal homeostasis in turbot (Scophthalmus maximus L.). Aquaculture 498, 335-342.

8. Zhou F, Wang Y-Q, Bei Y-J, et al. (2018) Assessing the efficacy of three methionine sources in low protein and low fish meal diet for Chinese soft-shelled turtle, Pelodiscus sinensis. Aquac Int 26, 15-26.

9. Kokou F, Sarropoulou E, Cotou E, et al. (2017) Effects of graded dietary levels of soy protein concentrate supplemented with methionine and phosphate on the immune and antioxidant responses of gilthead sea bream (Sparus aurata L.). Fish Shellfish Immunol 64, 111-121.

10. Gu M, Zhang WB, Bai N, et al. (2013) Effects of dietary crystalline methionine or oligo-methionine on growth performance and feed utilization of white shrimp (Litopenaeus vannamei) fed plant protein-enriched diets. Aquac Nutr 19, 39-46.

11. Yuan Y, Gong S, Yang H, et al. (2011) Effects of supplementation of crystalline or coated lysine and/or methionine on growth performance and feed utilization of the Chinese sucker, Myxocyprinus asiaticus. Aquaculture 316, 31-36.

12. Mai K, Wan J, Ai Q, et al. (2006) Dietary methionine requirement of large yellow croaker, Pseudosciaena crocea $\mathrm{R}$. Aquaculture 253, 564-572.

13. Niu J, Du Q, Lin H-Z, et al. (2013) Quantitative dietary methionine requirement of juvenile golden pompano Trachinotus ovatus at a constant dietary cystine level. Aquac Nutr 19, 677-686.

14. Li P, Burr GS, Wen Q, et al. (2009) Dietary sufficiency of sulfur amino acid compounds influences plasma ascorbic acid concentrations and liver peroxidation of juvenile hybrid striped bass (Morone chrysops $\times$ M. saxatilis). Aquaculture 287, 414-418.

15. Goff JB \& Gatlin DM (2004) Evaluation of different sulfur amino acid compounds in the diet of red drum, Sciaenops ocellatus, and sparing value of cystine for methionine. Aquaculture 241, 465-477.

16. Kelly M, Grisdale-Helland B, Helland SJ, et al. (2006) Refined understanding of sulphur amino acid nutrition in hybrid striped bass, Morone chrysops ox M. saxatilis o: sulphur amino acid nutrition of hybrid striped bass. Aquac Res 37, 1546-1555.

17. Xie J-J, Lemme A, He J-Y, et al. (2018) Fishmeal levels can be successfully reduced in white shrimp (Litopenaeus vannamei) if supplemented with DL-methionine (DL-Met) or DL-methionylDL-methionine (Met-Met). Aquac Nutr 24, 1144-1152.

18. Su Y-N, Wu P, Feng L, et al. (2018) The improved growth performance and enhanced immune function by DL-methionylDL-methionine are associated with NF- $\mathrm{kB}$ and TOR signalling in intestine of juvenile grass carp (Ctenopharyngodon idella). Fish Shellfish Immunol 74, 101-118.

19. EFSA Panel on Additives and Products or Substances used in Animal Feed (FEEDAP) (2015) Scientific opinion on the safety and efficacy of DL-methionyl-DL-methionine for all aquatic animal species. EFSA J 13, 4012.

20. Tarnecki AM, Burgos FA, Ray CL, et al. (2017) Fish intestinal microbiome: diversity and symbiosis unravelled by metagenomics. J Appl Microbiol 123, 2-17.
21. Butt RL \& Volkoff H (2019) Gut microbiota and energy homeostasis in fish. Front Endocrinol 10, 9.

22. Niu J, Chen X, Lu X, et al. (2015) Effects of different levels of dietary wakame (Undaria pinnatifida) on growth, immunity and intestinal structure of juvenile Penaeus monodon. Aquaculture 435, 78-85.

23. Lin S-M, Jiang Y, Chen Y-J, et al. (2017) Effects of astragalus polysaccharides (APS) and chitooligosaccharides (COS) on growth, immune response and disease resistance of juvenile largemouth bass, Micropterus salmoides. Fish Shellfish Immunol 70, 40-47.

24. Miller DM \& Aust SD (1989) Studies of ascorbate-dependent, iron-catalyzed lipid peroxidation. Arch Biochem Biophys 271, 113-119.

25. Chen Y, Zeng S-F \& Cao Y-F (2012) Oxidative stress response in zebrafish (Danio rerio) gill experimentally exposed to subchronic microcystin-LR. Environ Monit Assess 184, 6775-6787.

26. Song X, Wang L, Li X, et al. (2017) Dietary astaxanthin improved the body pigmentation and antioxidant function, but not the growth of discus fish (Symphysodon spp.). Aquac Res $\mathbf{4 8}$, $1359-1367$.

27. Caporaso JG, Kuczynski J, Stombaugh J, et al. (2010) QIIME allows analysis of high-throughput community sequencing data. Nat Methods 7, 335-336.

28. Li S, Zhang C, Gu Y, et al. (2015) Lean rats gained more body weight than obese ones from a high-fibre diet. Br J Nutr $\mathbf{1 1 4}$, 1188-1194.

29. Chen H \& Jiang W (2014) Application of high-throughput sequencing in understanding human oral microbiome related with health and disease. Front Microbiol 5, 508.

30. Gill SR, Pop M, DeBoy RT, et al. (2006) Metagenomic analysis of the human distal gut microbiome. Science 312, 1355-1359.

31. Magoc T \& Salzberg SL (2011) FLASH: fast length adjustment of short reads to improve genome assemblies. Bioinformatics $\mathbf{2 7}$, 2957-2963.

32. Edgar RC (2010) Search and clustering orders of magnitude faster than BLAST. Bioinformatics 26, 2460-2461.

33. Wang Q, Garrity GM, Tiedje JM, et al. (2007) Naive Bayesian classifier for rapid assignment of rRNA sequences into the new bacterial taxonomy. Appl Environ Microbiol 73, 5261-5267.

34. Lozupone C \& Knight R (2005) UniFrac: a new phylogenetic method for comparing microbial communities. Appl Environ Microbiol 71, 8228-8235.

35. Duncan DB (1955) Multiple range and multiple $\mathrm{F}$ tests. Biometrics 11, 1.

36. Santos LS, Htoo JK, Fracaroli C, et al. (2018) Bioavailability of di-peptide DL-methionyl-DL-methionine in comparison to DL-methionine in weaned and growing pigs. Anim Feed Sci Technol 241, 94-101.

37. Mamauag REP, Gao J, Thanh Nguyen B, et al. (2012) Supplementations of DL-methionine and methionine dipeptide in diets are effective for the development and growth of larvae and juvenile red sea bream, Pagrus major.J World Aquac Soc 43, 362-374.

38. Espe M, Andersen SM, Holen E, et al. (2014) Methionine deficiency does not increase polyamine turnover through depletion of hepatic S-adenosylmethionine in juvenile Atlantic salmon. Br J Nutr 112, 1274-1285.

39. Boonyoung S, Haga Y \& Satoh S (2013) Preliminary study on effects of methionine hydroxy analog and taurine supplementation in a soy protein concentrate-based diet on the biological performance and amino acid composition of rainbow trout [Oncorhynchus mykiss (Walbaum)]. Aquac Res 44, 1339-1347.

40. Alam MdS, Teshima S, Koshio S, et al. (2005) Supplemental effects of coated methionine and/or lysine to soy protein isolate diet for juvenile kuruma shrimp, Marsupenaeus japonicus. Aquaculture 248, 13-19. 
41. Pauly D \& Zeller D (2016) Catch reconstructions reveal that global marine fisheries catches are higher than reported and declining. Nat Commun 7, 10244.

42. Wu G, Wu Z, Dai Z, et al. (2013) Dietary requirements of 'nutritionally non-essential amino acids' by animals and humans. Amino Acids 44, 1107-1113.

43. Rezaei R, Wang W, Wu Z, et al. (2013) Biochemical and physiological bases for utilization of dietary amino acids by young pigs. J Anim Sci Biotechnol 4, 7.

44. Tong B \& Barbul A (2004) Cellular and physiological effects of arginine. Mini Rev Med Chem 4, 823-832.

45. Martínez Y, Li X, Liu G, et al. (2017) The role of methionine on metabolism, oxidative stress, and diseases. Amino Acids $\mathbf{4 9}$, 2091-2098.

46. Zhao W, Wang L, Liu M, et al. (2017) Transcriptome, antioxidant enzyme activity and histopathology analysis of hepatopancreas from the white shrimp Litopenaeus vannamei fed with aflatoxin B1 (AFB1). Dev Comp Immunol 74, 69-81.

47. Chen SJ, Guo YC, Espe M, et al. (2018) Growth performance, haematological parameters, antioxidant status and salinity stress tolerance of juvenile Pacific white shrimp (Litopenaeus vannamei) fed different levels of dietary myo-inositol. Aquac Nutr 24, 1527-1539.

48. Dawood MAO, Koshio S, El-Sabagh M, et al. (2017) Changes in the growth, humoral and mucosal immune responses following $\beta$-glucan and vitamin C administration in red sea bream, Pagrus major. Aquaculture 470, 214-222.

49. Feng L, Xiao W-W, Liu Y, et al. (2011) Methionine hydroxy analogue prevents oxidative damage and improves antioxidant status of intestine and hepatopancreas for juvenile Jian carp (Cyprinus carpio var. Jian): MHA improves antioxidant status of carp. Aquac Nutr 17, 595-604.

50. Elmada CZ, Huang W, Jin M, et al. (2016) The effect of dietary methionine on growth, antioxidant capacity, innate immune response and disease resistance of juvenile yellow catfish (Pelteobagrus fulvidraco). Aquac Nutr 22, $1163-1173$.

51. Adeoye AA, Yomla R, Jaramillo-Torres A, et al. (2016) Combined effects of exogenous enzymes and probiotic on Nile tilapia (Oreochromis niloticus) growth, intestinal morphology and microbiome. Aquaculture 463, 61-70.

52. Zhang M, Chekan JR, Dodd D, et al. (2014) Xylan utilization in human gut commensal bacteria is orchestrated by unique modular organization of polysaccharide-degrading enzymes. Proc Natl Acad Sci U S A 111, E3708-E3717.

53. Belkaid Y \& Hand TW (2014) Role of the microbiota in immunity and inflammation. Cell 157, 121-141.

54. Kamada N, Chen GY, Inohara N, et al. (2013) Control of pathogens and pathobionts by the gut microbiota. Nat Immunol 14, 685-690.

55. Snedeker SM \& Hay AG (2012) Do interactions between gut ecology and environmental chemicals contribute to obesity and diabetes? Environ Health Perspect 120, 332-339.

56. Johnson EL, Heaver SL, Walters WA, et al. (2017) Microbiome and metabolic disease: revisiting the bacterial phylum Bacteroidetes. J Mol Med 95, 1-8.

57. Mulder IE, Schmidt B, Stokes CR, et al. (2009) Environmentally-acquired bacteria influence microbial diversity and natural innate immune responses at gut surfaces. $B M C$ Microbiol 7, 79.

58. Mariat D, Firmesse O, Levenez F, et al. (2009) The Firmicutes/ Bacteroidetes ratio of the human microbiota changes with age. BMC Microbiol 9, 123.

59. Manco M, Putignani L \& Bottazzo GF (2010) Gut microbiota, lipopolysaccharides, and innate immunity in the pathogenesis of obesity and cardiovascular risk. Endocr Rev 31, 817-844.

60. Li J, Liu G, Li C, et al. (2018) Effects of different solid carbon sources on water quality, biofloc quality and gut microbiota of Nile tilapia (Oreochromis niloticus) larvae. Aquaculture 495, 919-931. 